DEPÓSITO LEGAL ZU2020000153

Esta publicación científica en formato digital

es continuidad de la revista impresa

ISSN 0041-8811

E-ISSN 2665-0428

Revista

de la

Universidad

del Tunlia

Fundada en 1947

por el Dr. Jesús Emrique Lossada

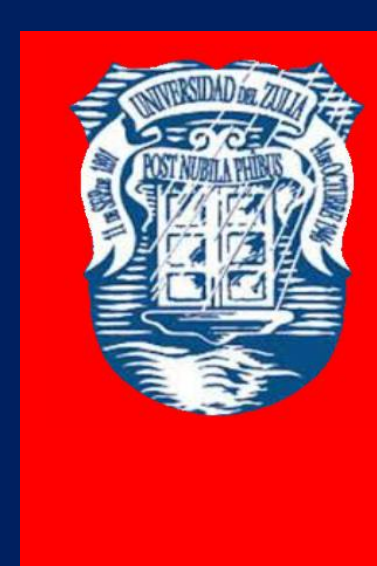

Ciencias

Sociales

y Arte

Aกัต 11 No 31

Septiembre - Diciembre 2021

Tercera ípoca

Maracailbo-Venezuela 


\section{Historia, verdad e ideología: sobre la historia oficial de Venezuela}

\section{Reyber Parra Contreras *}

Las corrientes historiográficas, entendidas como los distintos senderos que los historiadores han transitado en los últimos siglos a la hora de crear conocimiento histórico, se encuentran en contacto con dos extremos (tan distantes y tan cercanos a la vez) muy ligados con el conocimiento: verdad e ideología. Nos proponemos analizar brevemente la relación de la historia con estos conceptos, en el contexto de la constitución de una nueva historia oficial de Venezuela.

En razón de ello conviene precisar iqué es ideología? y iqué es la verdad?

Legaz y Lacambra (1971) entiende por ideología al conjunto de principios y postulados doctrinales con los cuales un sistema u orden expresa la idea o representación de si mismo, a fin de autolegitimarse en el tiempo. Por su parte, Ricoeur (1994) ubica la ideología en un nivel simbólico, que refuerza o crea una plusvalía en el plano de las creencias para satisfacer los requerimientos de la autoridad, es decir, su legitimación.

La verdad, entre tanto, es para Habermas (1989) el acuerdo en consenso entre todos los que tienen algo que decir o aportar acerca de un aspecto de la realidad, con base a la exposición de argumentos racionales. Tal apreciación pone de relieve que el hombre es ser racional y social, y que con base a estos atributos crea conocimiento. De ahí que, en cuanto a la correspondencia entre razonamiento y realidad, lo planteado por Habermas coincide con la definición clásica de la verdad o teoría del reflejo, según la cual un juicio es verdadero cuando lo que enuncia concuerda con su objeto (Schaff, 1982).

*Editor-Coordinador de la Revista de la Universidad del Zulia. ORCID: https://orcid.org/0000-00023231-9214. E-mail: reyberparra@gmail.com 
Goethe afirmaba que cada generación debe escribir de nuevo la historia, afirmación que Lucien Febvre complementa al señalar que "la historia es la necesidad que experimenta cada grupo humano, en cada momento de su evolución, de buscar y dar valor en el pasado a los hechos, las tendencias que preparan el tiempo presente (citado por Parra et al, 2015: 7). El historiador es quien canaliza esta aspiración o necesidad que brota de la condición temporal o historicidad de la humanidad. En efecto, para M. Oakeshott la historia es la experiencia del historiador" (citado por Parra et al., 2005: 10). No obstante, la mediación del historiador con respecto al estudio de los hechos del pasado y la necesidad de sus coetáneos de un cimiento identitario, no debe alejarse de la observancia de los lineamientos metodológicos que le confieren a la historia la posibilidad de aportar un relato de índole científico. Cuando el historiador orienta su labor a partir de las operaciones del método histórico, su relato aportará la verdad de los hechos y mantendrá a raya el contenido ideológico del mismo (sin que desaparezca por completo); de manera consecuente, al alejar su indagación del referido método, suprime la verdad y distorsiona los hechos al plagar el relato de ideología.

En efecto, no hay una verdad pura en la historia: hay una verdad que brota del rigor metodológico del historiador, la cual contiene en sí misma las expresiones de la subjetividad con la que este interpreta su mundo (ideología). Sin embargo, una subjetividad extracientífica (Schaff, 1982) cargada de intereses personales y fanatismo, introduce en el relato del historiador un tipo de ideología que lejos de coexistir con la verdad, la deforma hasta el punto de reemplazarla por la falsedad.

En las últimas décadas, la historia de Venezuela ha sido objeto de un inusitado interés reformista por parte de quienes ejercen el control político nacional. Reescribir la historia no es reprobable cuando se trata de esclarecer los hechos del pasado, aportar nuevas luces que permitan replantear la historia oficial y todas las versiones que supeditan la verdad a un cuerpo de creencias (ideología) sin fundamento en la realidad. Sin embargo, este no es el propósito de los impulsores de la nueva historia oficial.

En realidad, esta historia oficial se caracteriza por: 
- La visión maniquea de los hechos y personajes de la historia en función de reforzar un discurso populista y clasista, con el cual se busca adoctrinar y manipular a la población. Un caso concreto y notorio puede constatarse en la interpretación del pasado colonial, donde la crítica racional y fundamentada del statu quo de la época, es sustituida por una versión sectaria que estigmatiza, niega e invisibiliza la impronta del elemento hispano en la historia de Venezuela. En consecuencia, se cuestiona la escasa atención que la historiografía tradicional presta a la raíz indígena y africana de la cultura venezolana, y se intenta solucionar la cuestionada omisión, borrando de su relato el núcleo hispano de dicha cultura.

- La preminencia del mito por encima de los hechos, sobre todo cuando se trata de interpretar el período de la independencia y sus personajes relevantes. De esta manera, para la actual historia oficial, resulta importante ocultar el origen hispano y mantuano de Bolívar (Lombardi Boscán, 2020), a la par que se procura forzar una inexistente transición del pensamiento de Ezequiel Zamora a los predios del socialismo, en razón del capital simbólico que esto ofrece para la legitimación del orden actual a nivel de las masas.

- La descalificación de personajes de la historia de Venezuela, con énfasis en la etapa liberaldemocrática (Carrera Damas, 2008), por el vínculo ideológico que une a estos con quienes actualmente se oponen al modelo político imperante. La novel historia oficial condena el desempeño de los líderes fundadores de los principales partidos políticos venezolanos del siglo XX y desarrolla una interpretación sesgada e infundada de esta etapa, a tal punto de negar cualquier tipo de avance o aspecto positivo en la sociedad venezolana entre 1958 y 1998.

- El afán de novedad, de innovar en la reconstrucción de los hechos relevantes de la historia, pero sin rigor metodológico y por ende sin las evidencias que permitan sustentar tal novedad. El relato que se elabora termina repitiendo el discurso político de los líderes gubernamentales: "Es así como nace la nueva historiografía oficial en Venezuela (...) una historia parcial, politizada, y sesgada de los procesos" (Osorio, 2016: 188). 
Ciertamente, la historia oficial es propicia para la falsificación o deformación historiográfica, pues se desentiende de "propósitos científicos y se subordina por completo a los exclusivos requerimientos de la conducción política de las sociedades por los gobiernos y, sobre todo, por el sector socialmente dominante" (Carrera Damas, 1995: 394). Evidentemente que, al carecer de argumentos consistentes, resulta imposible que esta versión de la historia encuentre acogida y convenza al conjunto de los historiadores que tiene algo que decir acerca de la historia de Venezuela; por tanto, su relato no califica como verdadero, si nos atenemos al criterio propuesto por Habermas (1989) para caracterizar la verdad.

Corresponde a los historiadores (críticos, imparciales e inconformes ante el conocimiento existente) avanzar metódicamente en el estudio de la historia de Venezuela, con el propósito de armonizar la dualidad verdad-ideología en el plano historiográfico, y de esta manera proporcionar una interpretación veraz de la historia, alternativa y opuesta a la historia oficial.

\section{Referencias}

Carrera Damas, Germán (1995). Aviso a los historiadores críticos. Caracas: Ediciones Ge, C.A., p. 447. Carrera Damas, Germán (2008). Lo que fuimos, lo que somos y lo que seremos. Conferencia dictada el 27 de marzo de 2008 en la Cámara de Comercio de Caracas. http://www.ildis.org.ve/website/administrador/uploads/LoquefuimosCarreraDamas.pdf

Habermas, Jürgen (1989). Teoría de la Acción Comunicativa, Vol I. Madrid: Editorial Taurus.

Legaz y Lacambra, L. (1971). Ideología y principios fundamentales. Revista de Estudios Políticos, Número 175, Enero-Febrero 1971, 5-17. file://C:/Users/Reyber/Downloads/DialnetIdeologiaYPrincipiosFundamentales-1957233.pdf

Lombardi Boscán, Ángel (2020). España ignorada. Diario La Patilla, 12 de agosto de 2020. En: https://www.lapatilla.com/2020/08/12/angel-rafael-lombardi-boscan-espana-ignorada/

Osorio, Leonardo Favio (2016). La nueva historia oficial en Venezuela: el discurso historiográfico en el libro de historia contemporánea de la Colección Bicentenario, Tiempo y Espacio, 35 (66), 173 189. http://ve.scielo.org/pdf/te/v26n66/art09.pdf

Parra, Reyber: Ortega, Rutilio; Lárez, José (2005). Manual de Introducción a la Historia. Maracaibo: Universidad

Católica

Cecilio

Acosta. 
REVISTA DE LA UNIVERSIDAD DEL ZULIA. 3e época. Año $11 N^{\circ}$ 31, 2020 Reyber Parra Contreras/// Historia, verdad e ideología: sobre la historia oficial de Venezuela, 3-7 DOI: http://dx.doi.org/10.46925//rdluz.31.01

https://rive.google.com/file/d/lq6nSf3YLFPKKwbDKwqK7Ea-jWvTUzgSz/view DOI: https://doi.org/10.38186/ParraOrtegaLarez2005

Ricoeur, Paul (1994). Ideología y utopía. Traducción: Alberto L. Bixio. 2a edición. Barcelona. Gedisa Editorial, p. 360.

Schaff, Adam (1982). Historia y verdad. Ensayo sobre la objetividad del conocimiento histórico. México: Editorial Grijalbo, p. 373. 